\title{
Currículo como espaço-tempo de fronteira cultural*
}

\section{Elizabeth Macedo}

\author{
Universidade do Estado do Rio de Janeiro e Programa de Pós-Graduação em Educação
}

Em uma das mais importantes obras que discutem o papel da cultura na contemporaneidade, Jameson (2001) defende que, no atual estágio da globalização, economia e cultura tendem a coincidir. Em análise ácida, o autor sugere que essa coincidência reduz o potencial político do cultural ao exercício de práticas de escolhas ligadas ao consumo. Tendo em vista a centralidade da cultura na contemporaneidade, ressaltada por diferentes autores (García Canclini, 1998; Hall, 1997; Santos \& Nunes, 2003), essa observação de Jameson coloca-nos ante a uma série de questionamentos. Como pensar a ação política na sociedade contemporânea? Ainda há espaço para lutas em torno de princípios como igualdade e emancipação do sujeito?

* Este texto é parte do projeto "Currículo como entre-lugar identitário: raça, gênero e sexualidade nos currículos de ciências (1972-2001)", financiado pelo Conselho Nacional de Desenvolvimento Científico e Tecnológico (CNPq) e pela Fundação de Amparo à Pesquisa do Estado do Rio de Janeiro (FAPERJ). Conta, ainda, com bolsa de produtividade do Programa Prociência Universidade do Estado do Rio de Janeiro (UERJ/FAPERJ).
Tais questionamentos estão hoje no centro das discussões sobre currículo. Desde os anos de 1990, a centralidade da cultura nas sociedades contemporâneas tem propiciado uma guinada no campo rumo aos estudos culturais, a ponto de Pinar (2002) afirmar que a importância do entendimento do currículo como texto político foi substituída pelo "explosivo crescimento dos estudos culturais" (p. 114). Essa guinada, no entanto, defende o autor, não significa o abandono do interesse político que caracterizou os estudos sobre currículo, mas uma continuação desses interesses em um modelo que articula economia, política e cultura.

No sentido de pensar essa articulação, o que me parece fundamental para um campo que, como o do currículo, precisa responder a questionamentos de natureza política, defendo a posição de Santos e Nunes (2003), para quem é fundamental que se opere uma outra leitura do cultural. Uma leitura que não se fixe nas distinções entre cultura, economia e política, mas que entenda que o cultural, ao ser refuncionalizado como mercadoria, rearticula sua dimensão política. Uma leitura que perceba como o espaço-tempo da cultura incorpora valores de mercado, mas também 
alternativas que o tornam político por excelência. Uma leitura que, enfim, seja capaz de pensar o espaçotempo da política como um cruzamento entre características globais do capitalismo e especificidades locais em um processo que envolve hibridismos.

Entendo que a tarefa de uma tal leitura envolve conceitualizar o currículo como espaço-tempo cultural. Trata-se de tarefa que já vem sendo desenvolvida por diferentes autores, em um debate que põe em confronto, e por vezes associa, diversas perspectivas, a maioria de viés pós-crítico. No entanto, um dos aspectos que me parecem relevante destacar em relação ao hibridismo de perspectivas teóricas que tem caracterizado a discussão sobre currículo e cultura é a influência das teorias críticas. A observação de Pinar (2002), de que a maioria dos autores críticos passou a se dedicar ao estudo das interfaces entre currículo e cultura, parece real também para o Brasil ${ }^{1}$ e tem tido, ao meu ver, papel de relevo na conceitualização de cultura e de sua relação com o currículo. A centralidade da categoria conhecimento ${ }^{2}$ na teoria política de

1 O autor cita os casos de Michael Apple, Peter McLaren, Philip Wexler, Henry Giroux e Claude Bowers. No Brasil, Tomaz Tadeu da Silva dá guinada semelhante à descrita por Willian Pinar (cf. Lopes \& Macedo, 2002) e os trabalhos mais recentes de Antonio Flavio Barbosa Moreira também caminham nessa direção. No campo da didática, Vera Candau desenvolve trajetória similar.

2 A importância que a categoria conhecimento deteve no campo do currículo pode ser observada na síntese sobre pedagogia crítica, realizada por McLaren (1997). Uma simples referência a obras fundamentais do pensamento político em currículo mostra a centralidade da categoria: Conhecimento e controle: novas direções para a sociologia da educação, organizado por Young (1971); Conhecimento oficial, de Apple (1993); Estrutura, texto e disciplina: uma sociologia crítica do conhecimento escolar, de Wexler (1982). No Brasil, a obra clássica de Silva (1992) - O que se produz e o que reproduz em educação, e o número especial sobre currículo da revista Em Aberto (1993), assim como a análise de trabalhos apresentados na Associação Nacional de Pós Graduação e Pesquisa em Educação (ANPEd) (Macedo \& Fundão, 1996), mostram a relevância da temática no início dos anos de 1990. currículo, com forte acento crítico, parece permanecer subjacente às definições de cultura. O próprio Pinar (2002) argumenta que "ao se mover para os estudos culturais, nós, especialistas em currículo, estamos perguntando, como uma vez fizemos, que conhecimento é o mais válido" (p. 123).

No Brasil, a discussão sobre currículo e cultura tem sido desenvolvida nos últimos anos com influência dos estudos culturais e das discussões norte-americanas sobre multiculturalismo. Tem sido especialmente relevante nessa área o trabalho de Silva (1999a, 1999b), Canen e Moreira (2001), Moreira e Macedo (2002) e Moreira (2003). ${ }^{3}$ Em texto datado de 1994, Moreira e Silva (1994) já destacavam como tema central da análise crítica e sociológica do currículo a ideologia, a cultura e o poder. Ainda numa perspectiva crítica, os autores definiam currículo como "um terreno de produção e de política cultural" (p. 28). Chama a atenção no texto a centralidade dada às discussões sobre "o conhecimento corporificado no currículo" (idem, p. 29).

Em estudos mais recentes, Moreira tem discutido a temática do multiculturalismo, enfatizando e defendendo a aproximação entre abordagens críticas e pós-críticas (Moreira \& Macedo, 2002). Nesse sentido, embora analisando a diferença cultural no currículo, a centralidade da categoria conhecimento é claramente assumida pelo autor. Ainda que se preocupem em colocar o currículo a favor do processo de formação de novas identidades, Moreira \&

3 Conclusões semelhantes parecem-me poder ser derivadas da análise de outros autores do campo da educação como, por exemplo, Vera Candau. Em linha diversa, autores da pedagogia histórico-crítica, como José Carlos Libâneo e Selma Garrido Pimenta, vêm salientando mais recentemente dimensões culturais da prática pedagógica. Centro-me em Moreira e Silva (1994), tendo em vista a representatividade desses autores para o campo do currículo no Brasil. Em estado-da-arte do campo, analisando teses e dissertações de 1996 a 2002, esses autores são os nomes que destacadamente vêm influenciando a produção em currículo (Lopes, Macedo \& Paiva, 2006). 
Macedo explicitam a "intenção [de] que se reformule o conhecimento escolar de modo a favorecer a afirmação das identidades e dos pontos de vista de grupos minoritários" (p. 24). Em outro texto, em coautoria com Canen, Moreira destaca que "uma perspectiva multicultural deve informar os conteúdos selecionados em todas as áreas de conhecimento" (Canen \& Moreira, 2001, p. 32). Esses e outros exemplos ilustram o quanto a discussão de cultura e currículo empreendida por Moreira permanece tendo por horizonte questões postas pela teoria política do currículo sobre a seleção e organização do conhecimento escolar e sobre as relações de poder que lhes são subjacentes.

Já Silva, ao mesmo tempo em que explicitou sua preocupação com a discussão sobre cultura e currículo, assumiu uma posição mais claramente pósestrutural. Sua defesa da dimensão cultural do currículo veio associada, por exemplo, à definição do currículo como prática de significação (Silva, 1999a). Nesse sentido, seria de se esperar um maior afastamento das temáticas priorizadas pela teorização política de currículo, de viés crítico, especialmente no que se refere à centralidade do conhecimento. Entendo, no entanto, que esse afastamento, assim como a adesão à matriz pós-estrutural, deu-se de forma parcial, com a manutenção de categorias da teoria crítica. Ao apresentar uma concepção de currículo inspirada pelos estudos culturais, Silva (1999b) defende que ela "equipararia, de certa forma, o conhecimento propriamente escolar com, por exemplo, o conhecimento explícita ou implicitamente transmitido através de um anúncio publicitário" (p. 136). Para concluir, o autor comenta que "ambos os tipos de conhecimento estão envolvidos numa economia de afeto que busca produzir certo tipo de subjetividade e identidade social" (idem, ibidem). A linearidade com que a cultura vai cedendo espaço ao conhecimento ao longo do texto é acompanhada por uma agenda para o currículo que mescla o pósestruturalismo com preocupações ainda derivadas da teoria crítica - "o conteúdo do currículo é uma construção social” (idem, p. 135).
Em texto que me parece emblemático dessa mescla, Silva (1999a) defende que a cultura seja vista numa concepção não-essencialista, caracterizando-a como produção de sentido, como prática que envolve relações de poder e que produz identidades sociais. Embora concebendo currículo como prática produtiva e de significação, como relação social e de poder e como prática que produz identidades (e salientando o processo de produção cultural), o autor praticamente reedita preocupações da Nova Sociologia da Educação (Young, 1971, 1973). Ao analisar a política curricular, tanto em nível macro como micro, Silva assume uma visão reificada do currículo, entendendo-o como artefato que "tanto expressa as visões e os significados do projeto dominante quanto ajuda a reforçálas, a dar-lhes legitimidade e autoridade", que "tanto expressa essas visões e significados quanto contribui para formar as identidades sociais que lhes são convenientes" (p. 29). Sem deixar espaço para a ambigüidade - própria de uma concepção da política curricular mais processual -, Silva (1999b) defende que nós, professores, precisamos saber "qual é nosso lado nesse jogo?", um jogo de poder que, como lembrava Young (1973, p. 29), envolve “decisão moral, ética e política".

Selecionei essas passagens, não com o objetivo de dar conta da complexidade do pensamento de seus autores, mas apenas para pontuar como, a despeito de falar em práticas de significação, cultura, identidade, as preocupações da teorização política (e crítica) ainda informam os debates sobre currículo. Entendo que essa aproximação tem dificultado a compreensão da dinâmica do currículo como cultura e prejudicado a análise da diferença no interior do espaço-tempo da escola e do currículo. Não me parece produtivo assumir que esse espaço-tempo é um lugar de confronto entre culturas com lados definidos, nem que se deve optar por este ou aquele lado. De forma diversa, defendo que a diferença cultural não representa apenas "a controvérsia entre conteúdos oposicionais ou tradições antagônicas de valor cultural" (Bhabha, 1998, p. 228) e que, portanto, só pode ser captada em espaços-tempos liminares, num lugar-tempo em que 
há confronto, mas em que a opção possível estará sempre na nebulosa fronteira em que é preciso negociar, em que é preciso criar impossíveis formas de tradução. Por isso, meu objetivo neste texto é conceitualizar o currículo como um espaço-tempo de fronteira no qual interagem diferentes tradições culturais e em que se pode viver de múltiplas formas.

\section{Currículo como espaço-tempo de fronteira}

Pensar o currículo como espaço-tempo de fronteira, ${ }^{4}$ tendo como parceiros autores pós-coloniais, ${ }^{5}$ traz alguns perigos. Poder-se-ia argumentar que o póscolonialismo surgiu e desenvolveu-se para entender o hibridismo cultural de países que viviam sua independência política, sendo, portanto, imprópria a sua utilização para estudar, não apenas a realidade brasileira em que a descolonização política é muito mais antiga, como também uma questão tão específica como a educação ou, ainda mais especificamente, o currículo. Quanto à primeira, lanço mão de Bhabha (2002) quando expressa que entende por póscolonialismo a resistência a todas as formas de

4 Os autores pós-coloniais com os quais dialogo, entre os quais Bhabha (1998), Hall (2003) e García Canclini (1998), têm utilizado a idéia de fronteira (cultural) para nomear espaços em que culturas diferentes entram em contato. Não se trata de entender o conceito como limite geográfico, ainda que nesses espaços limítrofes pudéssemos falar de uma interação entre culturas nacionais.

5 Uso aqui a terminologia pós-colonial por ser essa a forma como vêm sendo tratados os autores que buscam analisar as trocas culturais depois de findo o colonialismo político. Trata-se de uma forma de diferenciar a perspectiva híbrida com que entendem o colonialismo dos modelos mais unilaterais de transferência, ou mesmo das leituras culturalistas que enfatizavam as resistências das culturas colonizadas. De qualquer forma, entendo, como Bhabha, que o discurso dito pós-colonial expressa a resistência a todas as formas de globalismos intensificadas com a queda do Muro de Berlim. globalismo, estendendo os questionamentos para o eurocentrismo ampliado ${ }^{6}$ presente em diversas manifestações contemporâneas. Quanto à segunda, mais do que citar estudos que têm feito excelentes leituras pós-coloniais da educação (como, por exemplo, Fleuri, 2001; Giroux, 2003; Ladwig, 2003), espero deixar clara a sua propriedade ao longo do texto. Parto do princípio de que o currículo é um espaço-tempo em que sujeitos diferentes interagem, tendo por referência seus diversos pertencimentos, e que essa interação é um processo cultural que ocorre num lugar-tempo cujas especificidades me interessam estudar. Não falo, portanto, de um espaço-tempo cultural qualquer, embora também dele, mas do currículo escolar (no Brasil de hoje). ${ }^{7}$

Quero, ainda, antes de ler esse currículo, deixar clara minha recusa em aceitar distinções entre o currículo formal e o vivido (em suas várias nuanças). Não me refiro apenas a distinções didáticas, mas principalmente às conseqüências que elas têm tido para o estudo das políticas e das práticas curriculares. Assumo, ao contrário, que a produção dos currículos formais e a vivência do currículo são processos cotidianos de produção cultural, que envolvem relações de poder tanto em nível macro quanto micro. Em ambos são negociadas diferenças. De ambos participam sujeitos culturais com seus múltiplos pertencimentos. Os materiais que usamos em nossas análises - um texto escrito ou o texto que escrevemos com nossas observações e entrevistas - parecem estar definindo

${ }^{6}$ A terminologia Europa amplia e expressa a aliança entre o Iluminismo europeu e a hegemonia contemporânea tanto política como cultural dos Estados Unidos.

7 Deixo claro que falo de um currículo escolar inexistente, posto que não alicerço estas considerações em nenhum resultado específico de pesquisa de campo. Ao contrário, falo de um currículo que é projetado em nossas falas e que é diferente para cada um de nós, sem generalizar, mas também sem particularizar. Não se trata de um ente abstrato, mas de um híbrido de minhas/nossas memórias e experiências. 
nossas distinções, mas certamente elas têm conseqüências políticas que precisam ser enfrentadas. De um lado, a maximização da importância dos mecanismos de controle formais via currículo dificulta a utilização dos espaços de resistência. De outro, a autonomização da resistência dificulta a percepção da complexidade do processo político e pode levar a uma certa espontaneidade. Defendo, subsidiada por Ball (1997), que os estudos de currículo precisam buscar compreender as relações entre as restrições e as possibilidades de ações como paradoxos, que podem ser vistos tanto no formal como no vivido. Para tanto, falo de currículo e me refiro indistintamente a processos que capto pela memória, ora de documentos curriculares, ora de escolas vivenciadas.

Antes, porém, de chegar a esse currículo vivenciado, creio oportuno pensar a própria educação, o significado do projeto de educar. À moda de Bhabha (1998) que, ao buscar entender a representação da nação percebe-a cindida e dupla, proponho que na produção da educação como narração percebamos a ambivalência conceitual que permite as variadas escrituras. Como na análise de Bhabha para o conceito de povo e de nação, a educação emerge de um movimento narrativo duplo: de um lado uma temporalidade continuista e de outro uma estratégia performática. Por temporalidade continuista, entendo todo um conjunto de saberes culturais legitimados, uma cultura eleita que é função do projeto educacional transmitir. ${ }^{8}$ Nesse sentido, a educação apresenta-se e autoriza-se como história, como espaço-tempo da repetição. Essa temporalidade continuista convive, no entanto, com uma outra temporalidade, que, como Bhabha, chamo de performática. Há, na

8 Refiro-me aqui não apenas, mas também, ao conhecimento acumulado, à cultura burguesa, aos princípios do Iluminismo ocidental, à cultura nacional, ao projeto de um mercado global que tendem a, de forma inquestionável, fazer parte do currículo escolar. Nego que apenas a pedagogia tradicional tenha como projeto a transmissão desses valores culturais e defendo que se trata de parte integrante do que entendemos por educação. educação, um projeto de significação que nega qualquer temporalidade anterior, qualquer referência a um passado essencialmente bom, o que seria a sua própria negação. ${ }^{9}$ A tensão entre repetição e performatividade cria uma zona de ambivalência, um espaçotempo liminar, em que é possível pensar a existência do outro. Um outro cultural que não é visto a partir das culturas legitimadas pelos currículos escolares, como seu avesso que está fazendo falta no currículo, mas que está lá na própria temporalidade introduzida pelo performativo. Uma temporalidade que, na expressão de Bhabha, é um entre-lugar que permite que as vozes marginais "não mais necessitem dirigir suas estratégias de oposição para um horizonte de 'hegemonia', que é concebido como horizontal e homogêneo" (1998, p. 213). Se pensarmos a educação nessa temporalidade, podemos conceber que nem as narrativas tradicionais da escola, nem os projetos críticos de formação de um cidadão emancipado, nem a hegemonia eurocêntrica ampliada, nem a colonização da escola pela ciência são capazes de impedir o surgimento e a construção de temporalidades disjuntivas. Esse é o pressuposto com o qual leio o currículo das nossas/minhas memórias.

Penso nos currículos escolares como espaçotempo de fronteira e, portanto, como híbridos culturais, ${ }^{10}$ ou seja, como práticas ambivalentes que incluem o mesmo e o outro num jogo em que nem a vitória nem a derrota jamais serão completas. Entendo-os como um espaço-tempo em que estão mesclados os discursos da ciência, da nação, do mercado, os "saberes comuns", as religiosidades e tantos outros, todos também híbridos em suas próprias constituições. É um espaço-tempo em que os bens simbólicos são "descolecionados", "desterritorializados", "impurifi-

\footnotetext{
9 Mesmo nas pedagogias tradicionais há uma utopia de cons-
} trução de uma sociedade mais harmônica, para a qual a educação desempenha papel fundamental.

${ }^{10}$ Para o conceito de híbrido cultural, ver García Canclini (1998) e Young (1995). Em texto de 2003, desenvolvo esse conceito em relação ao campo do currículo (Macedo, 2004). 
cados", num processo que explicita a fluidez das fronteiras entre as culturas do eu e do outro e torna menos óbvias e estáticas as relações de poder (García Canclini, 1998). Defendo que, nesse híbrido que é o currículo, tramas oblíquas de poder tanto fortalecem certos grupos como potencializam resistências. Em um e outro movimento, que são parte do mesmo, permitem que a diferença apareça na negociação "com as estruturas de violência e violação que (as) produziram" (Spivak, 1994, p. 199).

O entendimento do currículo como híbrido cultural parece-me crucial para pensar a diferença, não como diversidade (Burbules, 2003), mas como um discurso relacional em que o próprio sistema de sua representação está em questionamento. Como defende Skliar (2002), um outro que, ao contrário do outro multicultural, é político, "que não vive somente para contestar o malefício, que não se alinha facilmente a uma cultura que pode ser ordenada como múltipla, que não pode ser reduzido [...] a uma ação apenas relacional e comunicativa" (p. 202). Para pensar a diferença, passo a tratar, portanto, do currículo como espaço-tempo híbrido, de fronteira entre culturas que se legitimam de forma diferenciada.

Tratar o contemporâneo como espaço-tempo de fronteira é pensar em uma cultura global e homogênea, mas também em lógicas culturais alternativas. O espaço-tempo do currículo traz, sem dúvida, marcas de uma homogeneidade ditada tanto pela cultura do Iluminismo quanto por uma cultura de mercado, características do pensamento moderno e dentro das quais se torna difícil pensar a diferença. Para Santos (1997), o equilíbrio entre regulação e emancipação que caracterizaria a Modernidade foi sendo desestabilizado ao longo dos anos em um processo contraditório. O sentido dessa desestabilização apontou, no entanto, fortemente para a submissão da subjetividade (e da diferença individual) ao coletivo homogeneizado.

Em sua tentativa de compreender as lógicas culturais homogeneizantes da Modernidade, Santos (1997) argumenta que a função de regulação se fortaleceu em detrimento da emancipação. Para o autor, no capitalismo, o pilar da regulação foi caracterizado por uma hipertrofia do princípio de mercado em relação aos seus outros dois constituintes - os princípios de Estado e de comunidade - com três fases características. Do capitalismo liberal, com primazia absoluta do mercado, passou-se ao Estado-providência, em que, por pressão da comunidade, este dividia espaço com o Estado, e finalmente a uma retomada da hegemonia do princípio mercado. Interessa-me, nesse movimento, entender como a teoria liberal, que expressa esse desequilíbrio entre mercado, Estado e comunidade, levou à ocultação da diferença. Santos (1997) destaca que o liberalismo tentou compatibilizar as subjetividades individuais e coletivas por meio da distinção entre Estado e sociedade civil, regulando-a pelo princípio da cidadania. Se, por um lado, no entanto, a cidadania abre possibilidades de realização das subjetividades individuais (e das diferenças), por outro, cria uma individualidade abstrata e universal, que

\footnotetext{
transforma os sujeitos em unidades iguais e intercambiáveis no interior de administrações burocráticas públicas e privadas, receptáculos passivos de estratégias de produção, enquanto força de trabalho, de consumo, enquanto consumidores, e de estratégias de dominação, enquanto cidadãos da democracia de massas (p. 240).
}

Dessa forma, a cidadania, com sua marca de democracia e igualdade profundamente seletivas, dificulta a tematização da diferença no quadro da regulação do estado liberal. ${ }^{11}$

${ }^{11}$ É importante salientar que Santos (1997) enumera uma série de resistências aos princípios liberais, entre os quais o marxismo, o movimento estudantil e os novos movimentos sociais. Sobre o marxismo, o autor, embora salientando sua aguda capacidade crítica em relação ao Estado liberal, defende que o sujeito monumental do liberalismo foi substituído pela classe operária. Dessa forma, a homogeneização reguladora do Estado foi contraposta à homogeneização emancipadora de sujeitos coletivos. Em relação ao movimento estudantil, Santos defende que, a despeito 
Se, no âmbito da regulação, a marca da Modernidade parece ter sido a homogeneização, no pilar da emancipação a racionalidade cognitivo-instrumental da ciência teve primazia em detrimento das racionalidades moral-prática do direito e estético-expressiva da arte e da literatura. Para Santos (2000), esse duplo movimento de redução da emancipação à racionalidade cognitivo-instrumental e da regulação ao princípio de mercado acabou por reduzir, na Modernidade, a emancipação à regulação. Nas palavras do autor, "a emancipação deixou de ser o outro da regulação para se converter em seu duplo” (p. 57). São visíveis os efeitos da absorção da emancipação pela regulação em diferentes esferas do social, entre elas a escola e o currículo. Marcas como a relação entre escola e mercado de trabalho, a colonização do conceito de cidadania por práticas de mercado, a disciplinarização dos currículos, a sobrevalorização das ciências em detrimento das artes são exemplos, entre tantos outros, desses efeitos. Trata-se de marcas de uma tendência cultural dominante, cuja hegemonia no currículo tem sido questionada tanto pelas teorias críticas quanto pelo pós-estruturalismo.

Meu argumento central, no entanto, alicerça-se sobre as dificuldades que essas teorizações têm apresentado para pensar a diferença na sociedade moderna (e no currículo). No caso das teorias críticas, a vinculação da emancipação à idéia de classe condiciona a subjetividade individual à coletiva, dificultando a tematização da diferença. Em relação às teorizações pós-estruturais, concordo com Santos (1997) quando defende que Michael Foucault denuncia com propriedade o excesso de controle viabilizado pelo poder disciplinar (e pela ciência) - que regula e domestica corpos para maximizar sua utilidade social - ao mesmo tempo em que "exagera ao inscrever

de triunfar na substituição da cidadania homogeneizante por outra capaz de abarcar a subjetividade, negligenciou a cidadania liberal e acabou sendo desarmado com grande facilidade. Quanto às novas formas de resistências, capazes de tematizar a diferença, serão analisadas oportunamente. esse excesso de regulação na matriz do projeto de Modernidade, a ponto de fazer dele não só o único resultado, mas também o único resultado possível deste projeto" (p. 236). A essas dificuldades, contraponho as discussões pós-coloniais, que reconhecem a tendência cultural dominante como homogeneizadora (seguindo imperativos postos por um mercado e por uma ciência globais), ao mesmo tempo em que "não pode controlar ou saturar tudo dentro de sua órbita" (Hall, 2003, p. 59).

Centro, agora, minha atenção nos efeitos inesperados da homogeneização, ou seja, nas formações subalternas e nas tendências emergentes, salientadas por Hall (2003). Formações e tendências que não estão imunes aos princípios da homogeneização, mas que compõem um sistema cultural que não pode se estabilizar sem conter em si a diferença. Um sistema que nem "inaugura(m) formas totalmente distintas de vida" nem "conserva $(\mathrm{m})$ intactas as formas antigas e tradicionais" (p. 61). Em outras palavras, Hall defende que os sistemas globais convivem com localismos que eles mesmos produzem. Localismos que chocam suas distintas temporalidades com o desejo universal desses sistemas e só podem ser superados pela mediação do próprio sistema a que resistem (Santos \& Nunes, 2003).

Nas sociedades globais, os localismos assumem diferentes estratégias, do ressurgimento de pertencimentos étnicos a movimentos locais de resistência ao global. Santos e Nunes (2003) organizam as estratégias de resistência em dois grupos. Enquanto há estratégias que mobilizam os conceitos globais de forma transgressiva ou subversiva, há outras que denunciam esses conceitos e propõem conceitos alternativos. Além de não se poder, segundo os autores, estabelecer a primazia de umas sobre as outras, diferentes processos de hibridismo as têm articulado para responder a diversas situações históricas particulares. De qualquer forma, trata-se de estratégias que não criam algo de totalmente novo, diferente, mas que também não se localizam no tradicional marcado pelos globalismos. Como lembra Hall (2003), essas estratégias "constituem sítios potenciais de resistência, 
intervenção e tradução [...] [que] surgem de dentro do global sem ser simplesmente um simulacro deste" (p. 61). É importante ressaltar que não se trata de um conjunto de estratégias que pode ser pensado tendo em vista uma perspectiva transistórica ou estável. Ao contrário, elas habitam a conjuntura e possuem temporalidades distintas.

É, pois, na perspectiva de que, para além dos discursos homogeneizantes - do Iluminismo, do mercado, da nação -, o currículo escolar é habitado por uma diferença que não se define como a oposição ao homogêneo, que penso ser possível tratá-lo como uma espécie de espaço-tempo cultural liminar. Um espaçotempo em que as culturas presentes negociam com "a diferença do outro", ${ }^{12}$ que explicita a insuficiência de todo e qualquer sistema de significação. Tomando por empréstimo de Bhabha (1998) suas considerações sobre o processo de colonização cultural e político pelo qual passou a Índia, tento perceber o ato pedagógico na perspectiva de uma colonização dos saberes locais pelos sistemas globais hegemônicos no currículo. ${ }^{13}$ Essa tarefa pode parecer, à primeira vista, um tanto quanto fora de propósito, mas, como Ladwig (2003), acredito que "a descrição eloqüente e elaborada de Bhabha relativa ao hibridismo cultural diznos tanto sobre a colonização de nossos filhos quanto sobre a maldade cometida, tempos atrás, em terras bem distantes dos centros imperiais" (p. 277).

Assim, se o currículo pode ser visto como um espaço-tempo híbrido de fronteira, ele é também uma

12 É importante salientar que não se trata da idéia de negociação como apresentada pelas contribuições modernas, entre as quais se destaca a de Jürgen Habermas. A negociação tal como expressa por Bhabha parte da idéia de que a cultura é um espaço de enunciação e não um repertório de sentidos que podem ser negociados.

${ }^{13}$ Entendo colonização como a tentativa de espraiar para espaços-tempos locais ditames globais, utilizando-me da acepção que conferem ao termo, por exemplo, Bhabha (1998) e Hall (2003). Nesse sentido, não utilizo a terminologia globalização, na medida em que entendo se tratar de termo muito marcado pelo econômico. arena em que se dá uma experiência colonial. Nele convivem as culturas locais dos variados pertencimentos de alunos e professores com as culturas globais, majoritárias tanto nos currículos escritos quanto, possivelmente, nos vividos nas salas de aula. Nego, como querem algumas teorizações no campo do currículo, que os currículos oficiais sejam a expressão das culturas globais, enquanto os currículos em ação guardem distância segura em relação a essas culturas. Proponho que ambos sejam tratados como espaçostempos de colonização. Uma colonização que não é operada pelo professor sobre o aluno, como parece propor Ladwig (2003), mas por um híbrido Iluminismo/mercado sobre outros sistemas culturais. Defendo que tanto professor como aluno convivem com a proposta colonial de substituição de saberes menos organizados (ou sincréticos) $)^{14}$ por outros com nível maior de organização (ou sintéticos). Falo, portanto, de um colonialismo de que somos todos agentes, em maior ou menor grau, em momentos diversos.

A perspectiva de que o ato pedagógico e o currículo escolar sejam um espaço-tempo de colonização recoloca, em novos moldes, preocupações expressas pelas teorias da reprodução, que denunciavam o quanto a escola e o currículo estavam à mercê dos imperativos dos saberes dos grupos tanto cultural quanto economicamente hegemônicos. Muda a forma de enxergar a relação entre o hegemônico e o subalterno, o que permite que seja pensada a diferença nos currículos. A lição que Bhabha (1998) tira do colonialismo, e que pode nos ser útil, é que nenhuma dominação cultural é tão poderosa a ponto de minar os sistemas culturais locais. No entanto, é também verdade que nenhum sistema local fica imune ao colonialismo. Nenhuma diferença tem o poder de permanecer exis-

14 Uso aqui a terminologia tornada clássica por Dermeval Saviani e pela pedagogia histórico-crítica, sem nenhuma alusão exclusiva e este grupo como defensor de uma pedagogia colonial. Defendo que a tradição pedagógica tem como um de seus pilares o desejo iluminista do conhecimento, entendido como ciência e tecnologia. 
tindo a despeito da dominação, como nenhuma dominação acaba com a diferença.

Para explicitar a dominação colonial, Bhabha (1998) lança mão da noção de ambivalência, mostrando como o aparato discursivo colonial, ao mesmo tempo em que reconhece a diferença, a repudia, produzindo conhecimentos que são utilizados no exercício da vigilância. $\mathrm{O}$ outro é construído pelo discurso colonial com base em um discurso de oposição, que tem no estereótipo uma de suas principais estratégias, repetindo à exaustão o já sabido. Assim, no espaçotempo do currículo, tratado como espaço-tempo de hibridismo cultural, os outros saberes do currículo serão sempre tomados como o negativo do conhecimento acumulado. A insistência de diferentes discursos pedagógicos sobre a necessidade de partir do conhecimento do aluno, dos saberes prévios, da realidade concreta e tantos outros epítetos mostra o quanto é necessário nomear o outro. Ao repetir exaustivamente essa nomeação, a cultura iluminista da escola expõe, no entanto, a ambivalência que permeia seu desejo de dominação. A sua superioridade, que, se existe, deveria ser facilmente aceita, precisa, na verdade, ser constantemente salientada. Para isso, apóia-se numa fantasia de origem capaz de distingui-la das outras culturas, também elas fixadas por meio de estratégias discursivas estereotipadas.

A fantasia colonial do currículo alicerça-se, portanto, em objetos impossíveis, ou seja, numa pretensa diferenciação entre os saberes do Iluminismo, da escola, e aqueles trazidos por professores e alunos de sua vida cotidiana. Ocorre que essa distinção só é tornada possível por meio de estratégias de fixação, cuja ambivalência nega a sua própria possibilidade de existência. O discurso colonial, como nos lembra Bhabha (1998), apóia-se no reconhecimento e no repúdio à diferença, vivendo, portanto, sempre no espaço liminar em que é impossível a fixação de sentidos. O projeto iluminista, ao mesmo tempo em que despreza os outros saberes, afastando-os como o lugar do erro, torna-os próximos ao buscar colonizálos. O desejo do colonizador em relação ao colonizado - aquele que tem algo de que o colonizador não dispõe - torna a colonização total uma empreitada impossível.

Salientando as formas quase intransponíveis de ação do colonialismo, a preocupação de Bhabha em tematizar a possibilidade de entendimento dos discursos transgressores parece-me uma ferramenta útil para pensar uma política da diferença no currículo. Permite-nos perceber que as culturas presentes no espaço-tempo do currículo não podem ser fixadas, ainda que os discursos do Iluminismo - e aí se encontra boa parte de nossas teorias pedagógicas - busquem criar oposições e nos force a assumir uma posição de um ou de outro lado. O que Bhabha nos possibilita compreender é que as alternativas precisam ser construídas no entre-lugar desses supostos lados. No espaço-tempo liminar em que as culturas convivem e negociam sua existência. Uma negociação em que "nos identificamos com o outro exatamente no ponto em que ele é inimitável, no ponto em que se esquiva da semelhança" (Zizek apud Bhabha, 1998, p. 257).

\section{Um currículo da diferença cultural}

Ao pensar o currículo como espaço-tempo híbrido de fronteira, no qual culturas negociam sua existência (e inexistência em formas puras), acabo por retornar a questões que pontuei no início deste texto. Como lidar com as demandas por igualdade e diferença? Que tipo de decisões o espaço-tempo do currículo está a nos solicitar?

É já bastante batida a argumentação de que o pertencimento a uma identidade cultural particular implica o reconhecimento de outras identidades. Dessa forma, a afirmação das identidades particulares exigiria que não apenas as diferenças, mas os contextos em que se produzem, fossem reconhecidos, o que remete também à afirmação desse contexto. Numa perspectiva liberal, essa argumentação tem servido para massacrar a diferença, na propaganda de uma luta entre o particular e o universal, sempre "vencida" por este último. As ramificações dessas discussões no campo do currículo têm oposto, incessantemente, a cultura e o saber da escola àquele do aluno e da vida 
cotidiana, seja defendendo que os vencedores continuem ganhando, seja advogando em favor dos perdedores históricos.

Entendo, no entanto, que pensar um currículo da diferença envolve que a relação entre universal e particular, como propõe Laclau (1996), seja considerada num espaço cultural liminar em que cada identidade cultural é marcada pela ausência "de muitos outros", que são constitutivos de sua presença. Assim, para o autor, as várias identidades culturais marcam a incompletude de um certo horizonte universal, que será sempre redefinido de modo que nele possam ser negociadas as suas demandas particulares. Trata-se de um universal que se define na contingência, rearticulando os saberes e as culturas que resistem à totalização. Um universal que exige, portanto, uma negociação, na prática, entre tradições que não são apenas antagônicas, mas a marca mais forte da sua própria incompletude e da impossibilidade de um universal acima do particular.

O espaço-tempo do currículo, lido como uma performance cultural específica, contingente e particular, permite-nos acessar "os rastros de todos os discursos disciplinadores e instituições de saber que constituem a condição e os contextos da cultura" (Bhabha, 1998, p. 229), mas, mais que isso, nos impele a operar uma contextualização que não lança mão de causalidades ou origens dadas. Se as tradições globalizantes, em geral disciplinadoras (como lembra o pós-estruturalismo), são parte integrante do currículo, a função performática da educação e do currículo está em criar lugares-tempo híbridos de sentido. Nesses lugares-tempo, o ato de tradução cultural impede que as culturas globais vejam a si mesmas como completas, definitivas, e impõe as culturas subalternas como elemento que redesenha o global.

Espero que as considerações que desenvolvi ao longo do texto permitam a defesa do argumento de que um currículo, para lidar com a diferença, precisa ser pensado como espaço-tempo de negociação cultural. Com esse argumento pretendo também recuperar o potencial político da guinada do campo rumo aos estudos sobre cultura, não na perspectiva da teo- ria crítica e política do currículo, mas entendendo que é preciso pensar numa nova forma de agência. Uma agência que nos assume como produtores culturais, ${ }^{15}$ como defende Giroux (2001), uma agência que, nas palavras de Bhabha (1998), "requer uma fundamentação, mas não requer que a base dessa fundamentação seja totalizada; requer movimento e manobra, mas não requer uma temporalidade de continuidade e acumulação; requer direção e fechamento contingente, mas nenhuma teleologia e holismo" (p. 257). Um agente que está, enfim, numa posição de negociaçãocom-a-diferença.

\section{Referências bibliográficas}

APPLE, Michael. Official Knowledge. London: Routledge, 1993. BALL, Stephen. Educational reform: a critical and post-structural approach. Buckingham: Open University Press, 1997.

BHABHA, Homi. Conversation between John Comaroff and Homi Bhabha. In: GOLDBERG, David; AUAYSO, Ato (Orgs.). Relocating postcolonialism. New York: Blackwell, 2002. p. 17-36.

O local da cultura. Belo Horizonte: Editora da UFMG, 1998.

BURBULES, Nicolas C. Uma gramática da diferença: algumas formas de repensar a diferença e a diversidade como tópicos educacionais. In: GARCIA, Regina L.; MOREIRA, Antonio Flavio B. (Orgs.). Currículo na contemporaneidade: incertezas e desafios. São Paulo: Cortez, 2003. p. 159-188.

CANEN, Ana; MOREIRA, Antonio Flavio B. Reflexões sobre o multiculturalismo na escola e na formação docente. In: CANEN, Ana; MOREIRA, Antonio Flavio B. (Orgs.) Ênfases e omissões no currículo. Campinas: Papirus, 2001. p. 15-44.

${ }^{15}$ De certa forma, com essa preocupação retorno a uma filosofia do sujeito, recuperando aspectos do Iluminismo que vinha criticando ao longo do texto. Destaco essa preocupação, embora não saiba como resolvê-la neste momento de minhas discussões. Tenho imensa dificuldade em abrir mão de uma idéia de agência que, por fim, alicerça-se sobre a noção de hegemonia, categoria central das análises políticas. Tenho procurado pensar a questão da agência e da hegemonia, baseando-me tanto em Bhabha (1998) e Hall (2003) quanto em Laclau (1996). 
EM ABERTO. Currículo: referenciais e tendências. Brasília: INEP, 1993 (Número especial).

FLEURI, Reinaldo. Educação intercultural: mediações necessárias. Rio de Janeiro: DP\&A, 2001.

GARCÍA CANCLINI, Nestor. Culturas hibridas. São Paulo: EDUSP, 1998.

GIROUX, Henri. Atos impuros: a prática política dos estudos culturais. Porto Alegre: Artes Médicas, 2003.

. Cultural studies as performative politics. Cultural

studies - critical methodologies, v. 1, n. 1, p. 5-23, 2001.

HALL, Stuart. A centralidade da cultura: notas sobre as revoluções culturais do nosso tempo. Educação e Realidade, Porto Alegre: UFRGS, v. 22, n. 2, p. 15-46, 1997.

Da diáspora. Belo Horizonte: Editora da UFMG;

Brasília: Representação da UNESCO no Brasil, 2003.

JAMESON, Frederic. A cultura do dinheiro. Petrópolis: Vozes, 2001.

LACLAU, Ernest. Emancipación y diferencia. Buenos Aires: DIFEL, 1996.

LADWIG, John G. Primeiras aproximações a uma pedagogia mundial. In: GARCIA, Regina Leite; MOREIRA, Antonio Flavio B. (Orgs.). Currículo na contemporaneidade: incertezas e desafios. São Paulo: Cortez, 2003. p. 265-292.

LOPES, Alice C.; MACEDO, Elizabeth. O pensamento curricular no Brasil. In: . (Orgs.). Currículo: debates contemporâneos.

São Paulo: Cortez, 2002. p. 13-54.

LOPES, Alice; MACEDO, Elizabeth; PAIVA, Edil. Mapping researches on curriculum in Brazil. Journal of the American Association for the Advancement of Curriculum Studies, n. 2, p. 130, fev. 2006.

MACEDO, Elizabeth. Currículo e hibridismo: para politizar o conceito de cultura. Educação em Foco, Juiz de Fora: UFJF, v. 8, n. 1- 2, p. 13-30, 2004.

MACEDO, Elizabeth; FUNDÃO, Ana Paula. A produção do GT de currículo da ANPEd nos anos 90. In: REUNIÃO ANUAL DA ANPEd, 1996, Caxambu. Anais... Caxambu: ANPEd, 1996. p. 1-12.

MCLAREN, Peter. A vida nas escolas: uma introdução à pedagogia crítica nos fundamentos da educação. Porto Alegre: Artes Médicas, 1997.

MOREIRA, Antonio Flavio B. Currículo, diferença cultura e diálogo. Educação e Sociedade, Campinas: CEDES, v. 23, n. 79, p. 15-38, 2003.
MOREIRA, Antonio Flavio; SILVA, Tomaz Tadeu. Sociologia e teoria crítica do currículo: uma introdução. In: (Orgs.). Currículo, cultura e sociedade. São Paulo: Cortez, 1994. p. 7-37. MOREIRA, Antonio Flavio B.; MACEDO, Elizabeth. Currículo, identidade e diferença. In: (Orgs.). Currículo, práticas pedagógicas e identidades. Porto: Porto, 2002. p. 11-33.

PINAR, William. I am a man: the queer politics of race. Cultural studies - critical methodologies, v. 2, n. 1, p. 113-130, 2002.

SANTOS, Boaventura Sousa. A crítica da razão indolente. São Paulo: Cortez, 2000. . Pela mão de Alice. São Paulo: Cortez, 1997. .; NUNES, José A. Introdução: o cânone do reconhecimento, da diferença e da igualdade. In: SANTOS, Boaventura S. (Org.). Reconhecer para libertar. Rio de Janeiro: Civilização Brasileira, 2003. p. 25-68.

SILVA, Tomaz Tadeu. O currículo como fetiche. Belo Horizonte: Autêntica, 1999a.

. Documentos de identidade: uma introdução às teorias do currículo. Belo Horizonte: Autêntica, 1999b.

O que se produz e o que reproduz em educação. Porto Alegre: Artes Médicas, 1992.

SKLIAR, Carlos. A educação que se pergunta pelos outros: e se o outro não estivesse aqui? In: LOPES, Alice C.; MACEDO, Elizabeth (Orgs.). Currículo: debates contemporâneos. São Paulo: Cortez, 2002. p. 196-215.

SPIVAK, Gayatri. Quem reivindica a alteridade. In: HOLANDA, Heloisa.B. de (Org.). Tendências e impasses: o feminismo como crítica da cultura. Rio de Janeiro: Rocco, 1994. p. 53-75.

YOUNG, Michael. Knowledge and control: new directions for the sociology of education. Londres: Collier Macmillan, 1971.

Taking sides against the probable: problems of relativism and commitment in teaching and the sociology of knowledge. Educational Review, Londres, n. 25, p. 86-96, 1973. YOUNG, Robert. Colonial desire. London: Routledge, 1995.

WEXLER, Peter. Structure, text and subject: a critical sociology of school knowledge. In: APPLE, Michael (Org.). Culural and economic reproduction in education. London: Routledge \& Kegan Paul, 1982. p. 275-303.

ELIZABETH MACEDO, doutora em educação pela Universidade Estadual de Campinas (UNICAMP), é professora do Programa de Pós-Graduação em Educação da Universidade do Estado do Rio de Janeiro (UERJ). Publicou recentemente, em co- 
autoria com Alice Casimiro Lopes: Políticas de currículo em seus múltiplos contextos (São Paulo: Cortez, 2006), Cultura e política de currículo (Araraquara: Junqueira e Marin, 2006), Currículo de ciências em debate (Campinas: Papirus, 2004) e Currículo: debates contemporâneos (São Paulo: Cortez, 2002). Tem publicado também em revistas nacionais, como Educação \& Sociedade, Educação e Realidade, Educação em Foco, e internacionais, como o Journal of the American Association for the Advancement of
Curriculum Studies. Atualmente desenvolve o projeto "Currículo de ciências: uma abordagem cultural”, financiado pelo Conselho Nacional de Desenvolvimento Científico e Tecnológico (CNPq) e pela Fundação de Amparo à Pesquisa do Estado do Rio de Janeiro (FAPERJ).E-mail: bethmacedo@pobox.com

Recebido em outubro de 2005 Aprovado em dezembro de 2005 
context of the reconstruction of the public sphere in Latin America. It is argued, after returning to the social and pedagogical locations where popular education originated, that a distinctive trait of popular education is the notion of search itself, in the same sense that the Latin American identity itself constitutes a similar space of possibilities. This is followed by an analysis of some clandestine pedagogical strategies, thus understood since they are characterized respectively as absence or for what is hidden by hegemonic pedagogical theory: pedagogy of survival, of resistance, and of relation. At the end there is an allusion to the image of the labyrinth for defining the perplexities - past and present - of popular education.

Key-words: popular education; Latin America; public sphere; clandestine pedagogies

\section{La educación popular y la} reconstrucción del público. ¿Hay fuego sobre las brasas?

El artículo busca ubicar la educación popular en el contexto de la reconstrucción de la esfera pública en América Latina. A partir de la vuelta a sus orígenes para identificar el lugar social y los espacios pedagógicos en los cuales la misma se originó, argumenta que un trazo distintivo de la educación popular es la propia búsqueda, en el mismo sentido en que la identidad latinoamericana se constituye como este lugar de posibilidades. A seguir analiza algunas estrategias pedagógicas clandestinas, así entendidas por caracterizarse como ausencia u ocultación, respectivamente: pedagogía de la sobrevivencia, de la resistencia y de la relación. Al final, retorna a la imagen del laberinto para definir las perplexidades - históricas y actuales - de la educación popular.
Palabras claves: educación popular; América Latina; esfera pública; pedagogías clandestinas

Elizabeth Macedo

\section{Currículo como espaço-tempo de fronteira cultural}

A autora defende que o currículo precisa ser pensado como espaço-tempo de fronteira entre culturas, garantindo a centralidade da categoria cultura em detrimento do conhecimento, caro à pedagogia crítica e ainda hoje embasando as discussões do campo. Utiliza-se, na construção da argumentação, de discussões pós-coloniais, especialmente as contribuições de $\mathrm{H}$. Bhabha, S. Hall e B. S. Santos. Conclui que tratar o currículo como entre-lugar cultural em que se expressam princípios do Iluminismo e do mercado, mas também alternativas geradas na ambivalência dos globalismos, pode permitir ao currículo rearticular sua dimensão política na contemporaneidade. Palavras-chave: currículo; póscolonialismo; cultura

\section{Curriculum as the space-time of cultural frontier}

The author defends the position that the curriculum should be thought of as the space-time frontier between cultures. In so doing, the text proposes to guarantee the centrality of the category culture over knowledge, which is important to critical pedagogy and fundamental to the discussions within this field. Post-colonial theories as proposed by H. Bhabha, S. Hall and B. S. Santos are the theoretical contributions that sustain the argumentation. The text argues that to think about curriculum as a cultural in-between where we can find contributions from Illuminist theory and the market, as well as alternatives created in the ambivalence of these global discourses, can rearticulate the political dimension of curriculum in contemporary society.

Key-words: curriculum; post-

colonialism; culture

\section{Currículo como espacio-tiempo de frontera cultural}

La autora defiende que el currículo precisa ser pensado como espaciotiempo de frontera entre culturas, garantiendo la centralidad de la categoría cultural en detrimento del conocimiento, caro a la pedagogía crítica y todavía hoy sirve de base a las discusiones del campo. Se utiliza en la construcción de la argumentación, de discusiones pos-coloniales, especialmente las contribuciones de $H$. Bhabha, S. Hall y B. S. Santos. Concluye que tratar el currículo como entre-lugar cultural en que se expresan principios del iluminismo y del mercado, mas también alternativas generadas en la ambivalencia de los globalismos, puede permitir al currículo rearticular su dimensión politica en la contemporanidad.

Palabras claves: currículo; poscolonialismo; cultura

Rosanne Evangelista Dias e Rozana Gomes de Abreu

Discursos do mundo do trabalho nos livros didáticos do ensino médio

Neste estudo, focalizamos os discursos sobre o mundo do trabalho nos livros didáticos da área de ciências da coleção De olho no mundo do trabalho (editora Scipione), como parte de uma política curricular para o ensino médio. Entendemos a constituição de políticas curriculares como um processo de negociação complexo que inclui influência, produção e disseminação de textos circulantes que estão sujeitos à recriação contínua no contexto da prática (Ball). Analisamos como os discursos sobre o mundo do trabalho são apropriados e recontextualizados (Bernstein) na elaboração de livros di- 